\title{
Serum amyloid A3 expression is stimulated by dexamethasone and interleukin-6 in 3T3-L1 adipocytes
}

\author{
Mathias Fasshauer ${ }^{1}$, Johannes Klein ${ }^{2}$, Susan Kralisch ${ }^{1}$, \\ Margit Klier ${ }^{1}$, Ulrike Lossner ${ }^{1}$, Matthias Bluher ${ }^{1}$ and \\ Ralf Paschke ${ }^{1}$ \\ ${ }^{1}$ Department of Internal Medicine III, University of Leipzig, 04103 Leipzig, Germany \\ ${ }^{2}$ Department of Internal Medicine I, University of Lübeck, 23538 Lübeck, Germany \\ (Requests for offprints should be addressed to R Paschke; Email: pasr@medizin.uni-leipzig.de)
}

\begin{abstract}
A chronic increase in systemic levels of acute-phase reactants contributes to the development of insulin resistance and associated disorders such as cardiovascular disease. Recently, serum amyloid A3 (SAA3) has been characterized as an adipocyte-secreted acute-phase reactant, expression of which is dramatically increased in insulin resistance and obesity. To further clarify expression and regulation of this adipocytokine in fat, SAA3 mRNA was measured by quantitative real-time reverse transcriptase PCR during differentiation of 3T3-L1 adipocytes and after treatment with various hormones known to induce insulin resistance and contribute to atherosclerosis. SAA3 mRNA was dramatically induced up to 77-fold during differentiation of 3T3-L1 preadipocytes. Furthermore, $100 \mathrm{nM}$ dexa-
\end{abstract}

methasone and $30 \mathrm{ng} / \mathrm{ml}$ interleukin (IL)-6 induced SAA3 mRNA by up to 11 - and $4 \cdot 8$-fold, respectively, in a time-dependent fashion with significant stimulation observed at concentrations as low as $10 \mathrm{nM}$ dexamethasone and $1 \mathrm{ng} / \mathrm{ml} \mathrm{IL-6}$. In contrast, insulin, isoproterenol and growth hormone did not influence SAA3 synthesis. Inhibitor studies suggested that the positive effect of IL-6 on SAA3 expression is at least in part mediated by Janus kinase 2. Taken together, our results show a differential regulation of SAA3 by glucocorticoids and IL-6 supporting an integrative role of this acute-phase reactant in the pathogenesis of insulin resistance and its link to obesity and cardiovascular disease.

Journal of Endocrinology (2004) 183, 561-567

\section{Introduction}

Insulin resistance and type 2 diabetes are associated with obesity and cardiovascular disease. During the last couple of years a better understanding of the connection between increased adiposity on the one hand and impaired insulin sensitivity and cardiovascular disease on the other hand has been obtained (Fasshauer \& Paschke 2003). In particular, the central role of fat cell metabolism and secretion on whole-body glucose homeostasis and endothelial function has been well established. Thus, adipocytes secrete various proteins, including tumor necrosis factor (TNF) $\alpha$, interleukin (IL)-6 and resistin, which are upregulated in insulin resistance and profoundly impair insulin sensitivity (Fasshauer \& Paschke 2003). Furthermore, the adipocytokine adiponectin has been established as both an endogenous insulin sensitizer and a protector of endothelial function diminishing the development of atherosclerosis (Kubota et al. 2002). Moreover, various acute-phase reactants produced in fat cells and implicated in cardiovascular disease such as serum amyloid A3 (SAA3), $\alpha 1$-acid glycoprotein, plasminogen activator inhibitor-1 and fibrinogen are chronically increased in insulin resistance (Pickup et al. 1997). Recently, a report by Lin and co-workers (Lin et al. 2001) demonstrated that SAA3 is strongly upregulated in adipose tissue of obese mice as compared with lean controls and that white adipose tissue is a major source of this adipocyte-secreted protein. Furthermore, the authors demonstrated that SAA3 is stimulated by TNF $\alpha$ which has been shown to induce insulin resistance in vivo and in vitro (Lin et al. 2001). Thus, the data accumulated so far suggest that SAA3 is not only a well-known acute-phase reactant but also an adipocyte-secreted factor which might provide a molecular link between insulin resistance, obesity and cardiovascular disease. Therefore, we tested in the current study whether other hormones besides TNFa known to induce insulin resistance might alter SAA3 expression in 3T3-L1 adipocytes in vitro. We demonstrate for the first time that the glucocorticoid dexamethasone and the cytokine IL-6 potently induce SAA3 mRNA. Furthermore, we present evidence that the stimulatory effect of IL-6 is mediated via Janus kinase (Jak) 2. 


\section{Materials and Methods}

\section{Materials}

Cell-culture reagents were from Life Technologies (Grand Island, NY, USA), oligonucleotides were obtained from MWG-Biotech (Ebersberg, Germany) and AG490, LY294002, PD98059 and SB203580 were from Calbiochem (Bad Soden, Germany). All pharmacological inhibitors were used at concentrations that have been shown to potently inhibit the respective signaling molecule in 3T3-L1 adipocytes (Fasshauer et al. 2004a, M Fasshauer, U Lossner \& R Paschke, unpublished observations). Dexamethasone, growth hormone (GH), IL-6, insulin, isobutylmethylxanthine, isoproterenol and TNF $\alpha$ were obtained from Sigma Chemical Co. (St Louis, MO, USA).

\section{Culture and differentiation of 3T3-L1 cells}

3T3-L1 cells (American Type Culture Collection, Rockville, MD, USA) were differentiated as described previously (Fasshauer et al. 2001). In brief, confluent preadipocytes were cultured for 3 days in Dulbecco's modified Eagles medium containing $25 \mathrm{mM}$ glucose (DMEM-H), 10\% fetal bovine serum and antibiotics (culture medium) further supplemented with $1 \mu \mathrm{M}$ insulin, $0.5 \mathrm{mM}$ isobutylmethylxanthine and $0.1 \mu \mathrm{M}$ dexamethasone and an additional 3 days in culture medium with $1 \mu \mathrm{M}$ insulin. After another 3-6 days in culture medium about $95 \%$ of the cells showed accumulation of fat droplets. All treatments were carried out after serum starvation as further detailed in the figure legends.

\section{Analysis of $S A A 3 m R N A$ synthesis}

Expression of SAA3 mRNA was determined by quantitative real-time reverse transcriptase (RT) PCR in a Taqman fluorescence temperature cycler (Applied Biosystems, Darmstadt, Germany) as described previously (Fasshauer et al. 2004b). Briefly, after total RNA was isolated from 3T3-L1 adipocytes with TRIzol (Life Technologies), $1 \mu \mathrm{g}$ RNA was reverse-transcribed using standard reagents (Life Technologies). Ten per cent of each RT reaction was amplified in a $26 \mu \mathrm{PCR}$ using the Brilliant SYBR Green QPCR Core Reagent Kit from Stratagene (La Jolla, CA, USA) according to the manufacturer's instructions. Samples were incubated in the Taqman for an initial denaturation at $95^{\circ} \mathrm{C}$ for $10 \mathrm{~min}$ after which 40 PCR cycles were performed, each cycle consisting of $95{ }^{\circ} \mathrm{C}$ for $15 \mathrm{~s}, 60{ }^{\circ} \mathrm{C}$ for $1 \mathrm{~min}$ and $72{ }^{\circ} \mathrm{C}$ for $1 \mathrm{~min}$. The following primers were used: SAA3 (accession no. NM_011315), 5'-GTTCACGGGACATGGAGC AGAGGA-3' (sense) and 5'-GCAGGCCAGCAGGT CGGAAGTG-3' (antisense); 36B4 (NM007475) 5'AAGCGCGTCCTGGCATTGTCT-3' (sense) and $5^{\prime}$ CCGCAGGGGCAGCAGTGGT-3' (antisense). SYBR
Green I fluorescence emissions were monitored after each cycle and expression of SAA3 and 36B4 mRNA was quantified by the second derivative maximum method of the Taqman software (Applied Biosystems). This method determines the crossing points of individual samples by an algorithm identifying the first turning point of the fluorescence curve. SAA3 expression was calculated relative to 36B4 which was used as an internal control due to its resistance to hormonal regulation (Laborda 1991). Amplification of specific transcripts was confirmed by melting curve profiles (cooling the sample to $68^{\circ} \mathrm{C}$ and heating slowly to $95{ }^{\circ} \mathrm{C}$ with measurement of fluorescence) at the end of each PCR.

The specificity of the PCR was further verified by subjecting the amplification products to agarose gel electrophoresis and restriction analysis (data not shown).

\section{Statistical analysis}

Results are shown as means \pm S.E. Differences between various treatments were analysed by unpaired Student's $t$-tests. $P<0.01$ was considered highly significant and $P<0.05$ significant. The number of independent single experiments performed is indicated in the figure legends.

\section{Results}

\section{Quantification of SAA3 mRNA levels in 3T3-L1 fat cells}

First, the reliability of the quantitative real-time RT-PCR method was tested. For this purpose, increasing amounts of total cellular RNA were reverse-transcribed and quantified using specific primer pairs for SAA3. As shown in Fig. 1, linearity between total RNA used per reaction and amount of mRNA measured by the Taqman software was obtained between 2 and 200 ng total RNA.

\section{$S A A 3 m R N A$ is induced during differentiation}

Expression of SAA3 mRNA during differentiation of 3T3-L1 cells was determined. The acute-phase reactant was strongly induced 77-fold on day 3,63-fold on day 6 and 57-fold on day 9 of differentiation as compared with undifferentiated preadipocytes (day $0 ; P<0 \cdot 01$; Fig. 2).

\section{Dexamethasone and IL-6 are novel stimulators of SAA3 synthesis}

Various hormones inducing insulin resistance in vivo and in vitro were tested concerning regulation of SAA3. Treatment of 3T3-L1 adipocytes with $100 \mathrm{nM}$ dexamethasone for $16 \mathrm{~h}$ significantly induced SAA3 expression 11-fold $(P<0 \cdot 01$; Fig. 3). Furthermore, $30 \mathrm{ng} / \mathrm{ml}$ IL-6 significantly induced SAA 3 mRNA synthesis $2 \cdot 7$-fold $(P<0 \cdot 01$; Fig. 3). In contrast, insulin, isoproterenol and GH did not significantly influence expression of SAA3 (Fig. 3). 


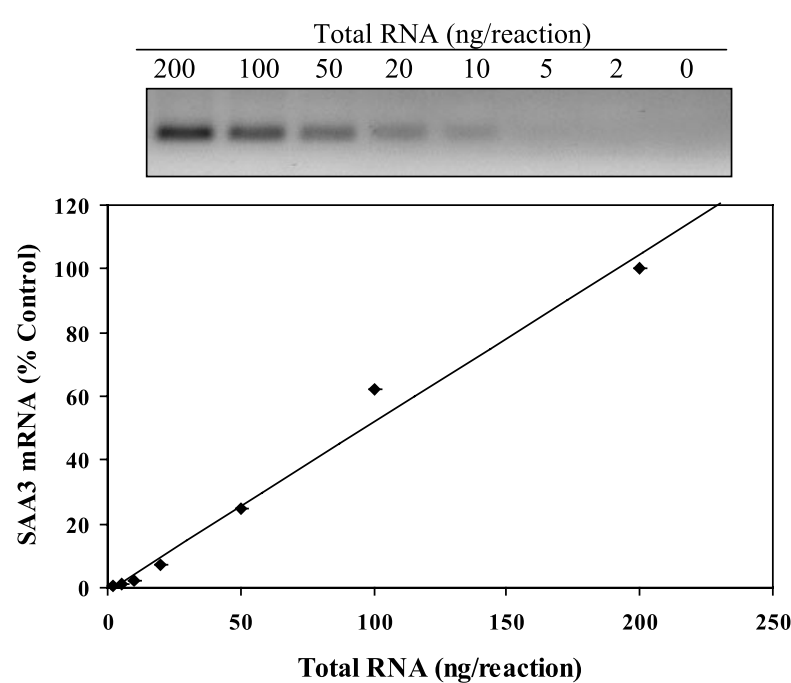

Figure 1 Quantification of SAA3 mRNA in 3T3-L1 fat cells. Increasing amounts of total RNA from differentiated 3T3-L1 adipocytes were subjected to quantitative real-time RT-PCR with primers specific for SAA3 as described in the Materials and Methods section. Data are shown relative to mRNA levels measured with $200 \mathrm{ng}$ RNA (=100\%). Results are the means from three independent experiments. Top panel, agarose gel electrophoresis of the PCR product at cycle 31 .

Dexamethasone induced SAA3 time-dependently with maximal $9 \cdot 1$-fold upregulation detectable after $8 \mathrm{~h}$ of treatment and significant stimulation persisting for up to $24 \mathrm{~h}(P<0 \cdot 05$; Fig. 4A). Moreover, stimulation of SAA3 was dose-dependent with significant $3 \cdot 3$-fold induction first seen at $10 \mathrm{nM}$ effector and a maximal 9.8-fold increase at $1000 \mathrm{nM}$ dexamethasone $(P<0 \cdot 05$; Fig. 4D). IL-6 $(30 \mathrm{ng} / \mathrm{ml})$ significantly activated SAA3 expression in

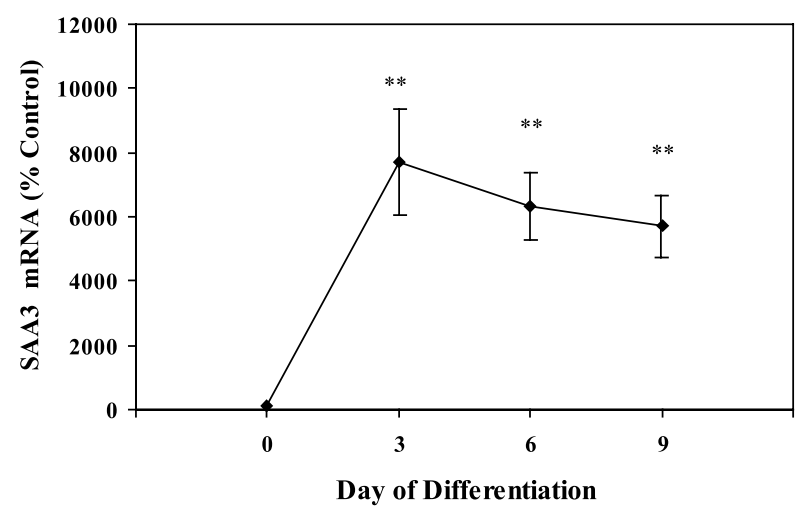

Figure 2 SAA3 expression during differentiation. Confluent preadipocytes (day 0) were induced to differentiate and, at the days indicated, total RNA was subjected to quantitative real-time RT-PCR. SAA3 mRNA expression is presented relative to preadipocytes on day $0(=100 \%)$. Results are the means \pm S.E. from four independent experiments. ${ }^{*} P<0 \cdot 01$, comparing confluent cells (day 0 ) with differentiating adipocytes (days 3, 6 and 9).

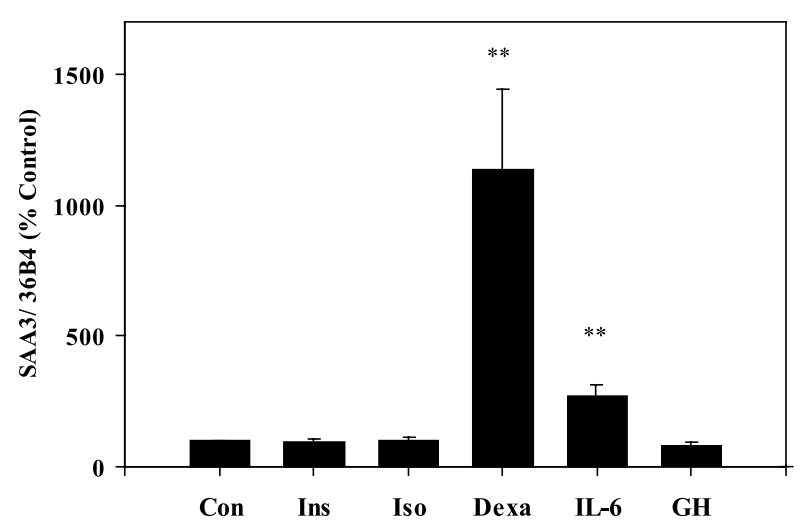

Figure 3 SAA3 mRNA synthesis is stimulated by dexamethasone and IL-6. Fully differentiated 3T3-L1 cells were serum deprived for $16 \mathrm{~h}$ before $100 \mathrm{nM}$ insulin (Ins), $10 \mu \mathrm{M}$ isoproterenol (Iso), $100 \mathrm{nM}$ dexamethasone (Dexa), $30 \mathrm{ng} / \mathrm{ml} \mathrm{IL-6}$ and $500 \mathrm{ng} / \mathrm{ml} \mathrm{GH}$ were added for $16 \mathrm{~h}$. After total RNA isolation, quantitative real-time RT-PCR was performed determining SAA3 mRNA levels normalized to 36B4 relative to untreated control (Con) cells $(=100 \%)$ as described in the Materials and Methods section. Results are the means \pm S.E. from at least three independent experiments. ${ }^{*}$ Highly significant $(P<0 \cdot 01)$ differences comparing hormone-treated with non-treated cells.

a time-dependent manner with 1.4-fold stimulation observed as early as $1 \mathrm{~h}$ after IL- 6 addition and maximal $4 \cdot 8$-fold induction after $24 \mathrm{~h}$ of treatment $(P<0 \cdot 05$; Fig. 4B). Furthermore, IL-6 induced SAA3 mRNA more than 3 -fold at concentrations as low as $1 \mathrm{ng} / \mathrm{ml}(P<0 \cdot 05$; Fig. 4E). Moreover, TNF $\alpha$ stimulated SAA3 expression in a time- and dose-dependent fashion with significant induction seen as early as $2 \mathrm{~h}$ after effector addition $(P<0 \cdot 05$; Fig. $4 \mathrm{C})$ and at concentrations as low as $1 \mathrm{ng} / \mathrm{ml}$ TNF $\alpha(P<0 \cdot 05$; Fig. 4F).

The stimulatory effect of IL-6 on SAA3 synthesis is mediated via Jak2

Finally, we tested which molecules implicated in IL-6signaling potentially mediate induction of SAA3 synthesis. To this end, 3T3-L1 fat cells were pretreated with specific pharmacological inhibitors of Jak2 (AG490; $10 \mu \mathrm{M}$ ), p44/42 mitogen-activated protein kinase (MAP kinase; PD98059; $50 \mu \mathrm{M})$, p38 MAP kinase (SB203580; $20 \mu \mathrm{M})$ or phosphoinositide 3-kinase (PI 3-kinase; LY294002; $10 \mu \mathrm{M}$ ) for $1 \mathrm{~h}$ before $30 \mathrm{ng} / \mathrm{ml}$ IL-6 was added for $16 \mathrm{~h}$. Treatment of 3T3-L1 adipocytes with PD98059 and LY294002 alone significantly increased basal SAA3 expression $(P<0 \cdot 01)$ whereas AG490 and SB203580 did not have any effect (Fig. 5). Again, SAA3 synthesis significantly increased 4.2-fold after IL-6 addition $(P<0 \cdot 01$; Fig. 5). This induction was significantly blunted in cells pretreated with the Jak2 inhibitor AG490 to $167 \%$ of control levels $(P<0 \cdot 05$; Fig. 5). In contrast, addition of the p44/42 MAP kinase inhibitor PD98050 and the PI 
A

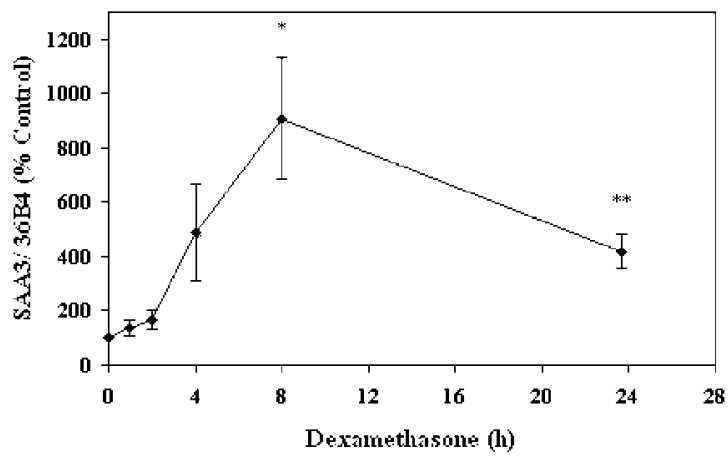

B

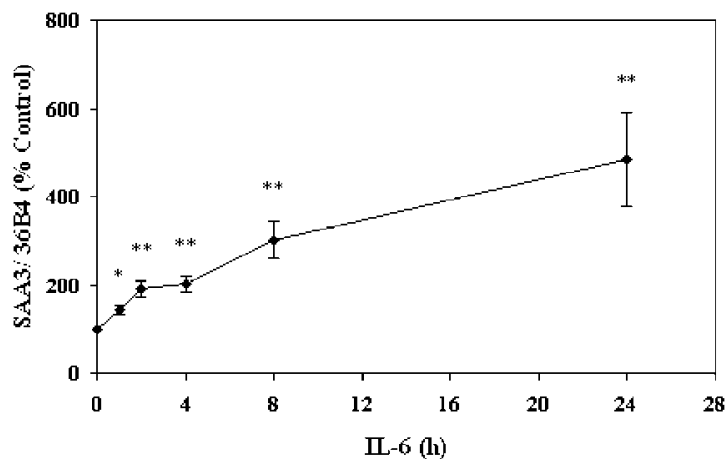

$\mathrm{C}$

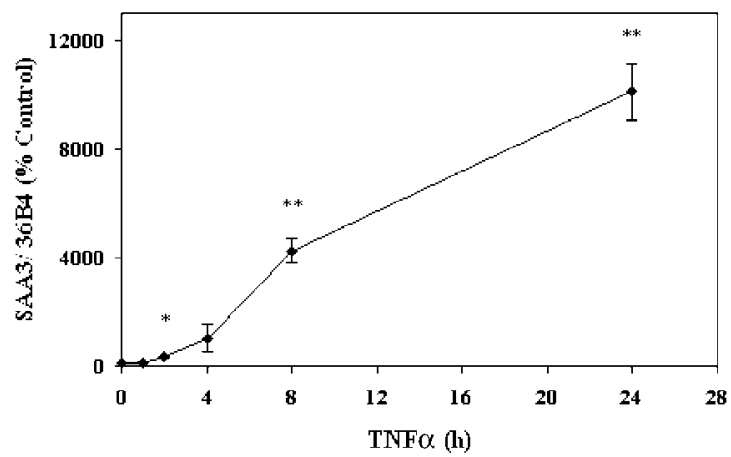

D

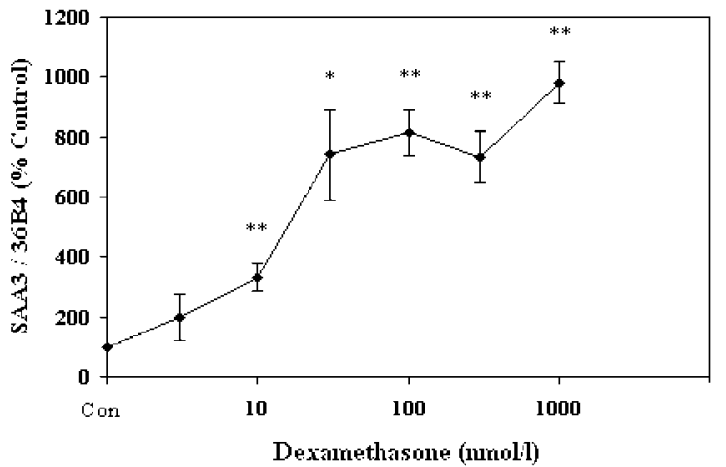

E

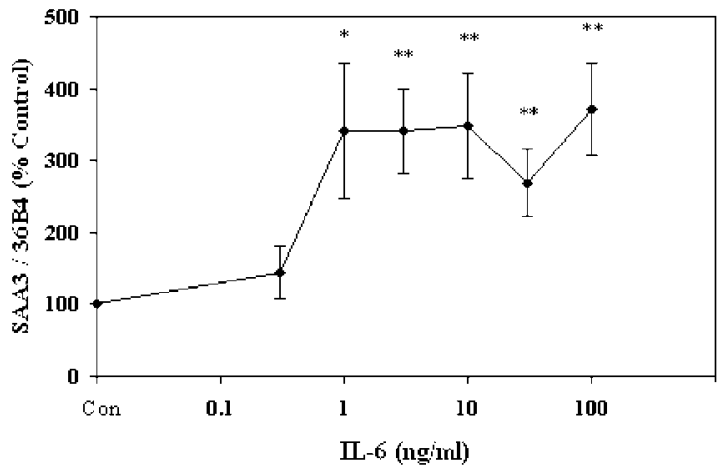

F

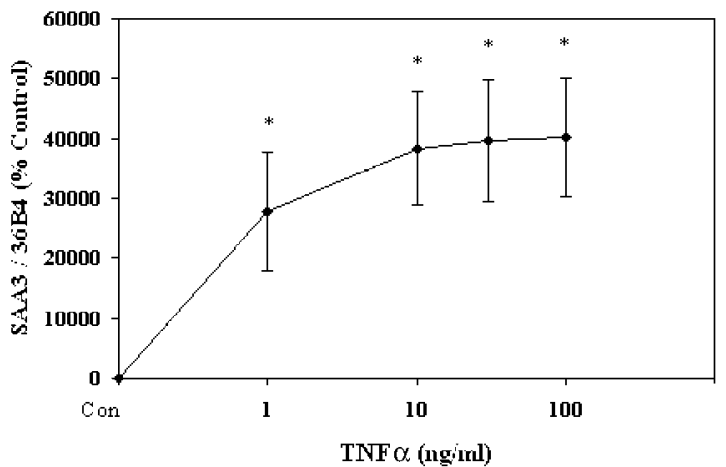

Figure 4 Dose- and time-dependent upregulation of SAA3 expression by dexamethasone, IL- 6 and TNF $\alpha$. 3T3-L1 cells were serum starved for $16 \mathrm{~h} \mathrm{(A-C)}$ or $6 \mathrm{~h}(\mathrm{D}-\mathrm{F})$ before (A) $100 \mathrm{nM}$ dexamethasone, (B) $30 \mathrm{ng} / \mathrm{ml} \mathrm{IL}-6$ and (C) $20 \mathrm{ng} / \mathrm{ml}$ TNF $\alpha$ were added for the indicated periods of time or the indicated concentrations of (D) dexamethasone, (E) IL- 6 and (F) TNF $\alpha$ were added for $16 \mathrm{~h}$. Total RNA was extracted and subjected to quantitative real-time RT-PCR determining SAA3 mRNA levels normalized to 36B4 as described in the Materials and Methods section. Data are expressed relative to untreated control (Con) cells ( $=100 \%)$. Results are the means \pm S.E. from at least three independent experiments. ${ }^{* *}$ Highly significant $(P<0 \cdot 01)$, *significant $(P<0 \cdot 05)$ differences comparing hormone-treated with non-treated cells.

3-kinase inhibitor LY294002 augmented IL-6-induced SAA3 expression; however, only in the case of PD98059 was statistical significance reached $(P<0 \cdot 05$; Fig. 5). SB203580-preincubation did not significantly influence IL-6-induced SAA3 expression (Fig. 5).

\section{Discussion}

During the last couple of years, it has been suggested that an ongoing cytokine-mediated acute-phase response initiated by the body's innate immune system might be an important contributor to insulin resistance and its link to other accompanying disease states including obesity and atherosclerosis (Pickup \& Crook 1998). Although the liver has been conventionally considered as the major site of many acute-phase reactants, cytokine production by fat tissue has become a focus of current research since fat cells themselves and macrophages infiltrating adipose tissue produce various proinflammatory cytokines including TNF $\alpha$, IL-6, monocyte chemoattractant protein 1 and 


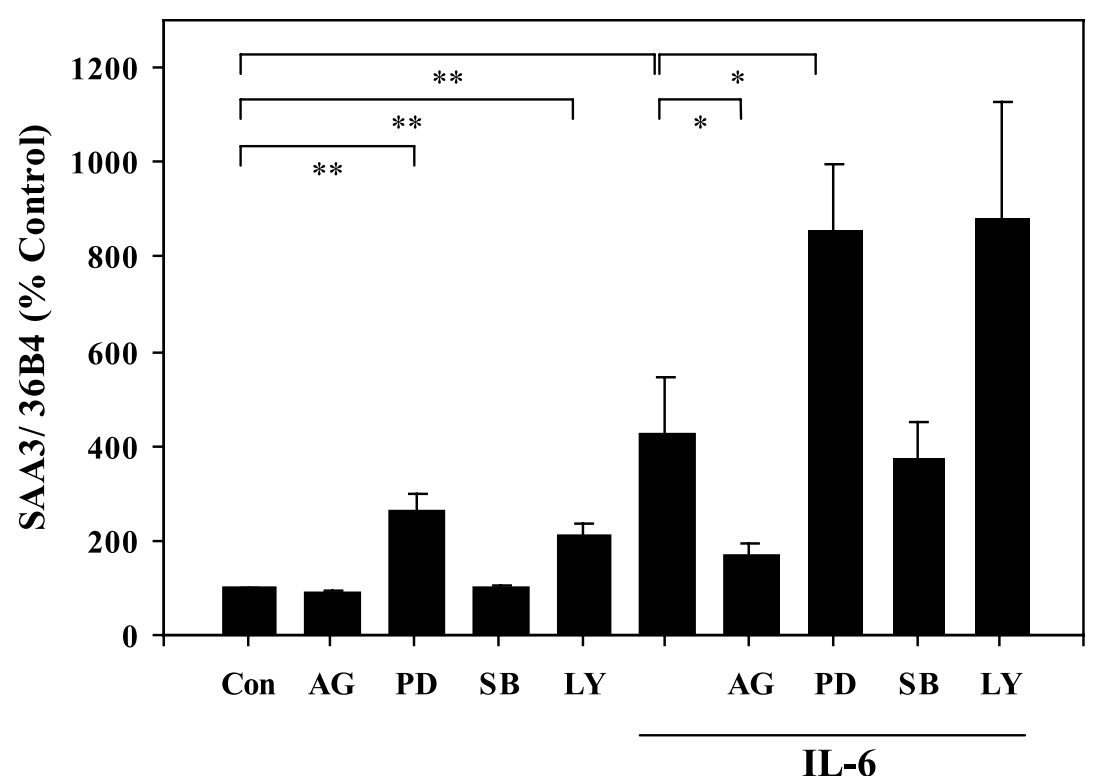

Figure 5 Signaling molecules mediating induction of SAA3 by IL-6. After serum starvation for $5 \mathrm{~h}, 3 \mathrm{~T} 3-\mathrm{L} 1$ adipocytes were cultured in the presence or absence of AG490 (AG; $10 \mu \mathrm{M})$, PD98059 (PD; $50 \mu \mathrm{M}), \mathrm{SB} 203580$ (SB; $20 \mu \mathrm{M})$ or LY294002 (LY; $10 \mu \mathrm{M})$ for $1 \mathrm{~h}$ before $30 \mathrm{ng} / \mathrm{ml} \mathrm{IL-6}$ was added for $16 \mathrm{~h}$. After RNA extraction and reverse transcription, quantitative real-time RT-PCR was performed to determine SAA3 normalized to 36B4 as described in the Materials and Methods section. Data are expressed relative to non-treated control (Con) cells $(=100 \%)$ and the results are the means \pm S.E. from three independent experiments. ${ }^{*} P<0 \cdot 01,{ }^{*} P<0 \cdot 05$ comparing effector-treated with non-treated and inhibitor-pretreated adipocytes.

SAA3 (Weisberg et al. 2003, Wellen \& Hotamisligil 2003, $\mathrm{Xu}$ et al. 2003). Among these, SAA3 is a member of a family of at least four highly homologous high-density lipoprotein (HDL) apoproteins actively transcribed in mice. In contrast to SAA1, SAA2 and SAA5, SAA3 mRNA is expressed in many tissues including fat, liver and macrophages (Meek et al. 1992). All SAA family members share an amphipathic helical structure which appears essential for their lipid-associating character. The function of adipocyte-derived SAA3 and other SAA family members has become more evident in recent years. Thus they displace apolipoproteins A1 and E from HDL, thereby increasing HDL binding to macrophages and impairing HDL clearance in the liver (Meek et al. 1992). Therefore, SAA proteins may contribute to dyslipidemia associated with insulin resistance and promote cardiovascular disease. In agreement with this notion, increased SAA levels at baseline predict an increased risk of patients suffering from future coronary artery occlusion (Ridker 1999). In a recent study, SAA3 was shown to be upregulated in obesity in vivo and by TNF $\alpha$ and lipopolysaccharide in adipocytes in vitro (Lin et al. 2001).

Glucocorticoids have been demonstrated to cause insulin resistance in vivo (Andrews \& Walker 1999). In the current study, we show for the first time that dexamethasone potently induces SAA3 expression in 3T3-L1 adipocytes in vitro. These findings indicate that upregulation of SAA3 may be one mechanism by which impaired insulin sensitivity in hypercortisolism is linked to obesity and increased cardiovascular risk. However, glucocorticoid-induced downregulation of the endogenous insulin sensitizer and vascular protector adiponectin in fat cells probably also contributes (Fasshauer et al. 2002). In vivo data from patients with Cushing's syndrome will be helpful to further define the role of SAA3 and adiponectin in glucocorticoid-induced insulin resistance, adiposity and endothelial dysfunction. Furthermore, our data indicate that despite their profound anti-inflammatory effects used in clinical medicine, glucocorticoids are able to differentially regulate acute-phase mediators. Thus, SAA3 expression is induced by dexamethasone whereas the major proinflammatory cytokine IL-6 is, in fact, downregulated (Fasshauer et al. 2003a).

IL-6 has been implicated as an important proinflammatory cytokine, plasma concentrations of which correlate with the development of insulin resistance and cardiovascular disease (Tsigos et al. 1997, Pradhan et al. 2001). Administration of recombinant IL-6 in rodent models and humans in vivo induces hepatic gluconeogenesis which, in turn, leads to hyperglycemia and compensatory hyperinsulinemia (Stith \& Luo 1994, Tsigos et al. 1997). In the current study, we demonstrate for the first time that SAA3 
is upregulated by IL-6 in vitro in 3T3-L1 fat cells. Therefore, our data suggest that increased levels of this acute-phase reactant may contribute to IL-6-induced insulin resistance and vascular dysfunction besides other well-studied mechanisms including induction of IL-6 itself (Fasshauer et al. 2003a) and suppression of adiponectin (Fasshauer et al. 2003b). IL-6 induces homodimerization of its receptor gp130 at the plasma membrane, thereby activating associated kinases such as Jaks and Tyk2 which phosphorylate the cytoplasmic tail of gp130 (Heinrich et al. 1998). In the current study, we show that pharmacological inhibition of Jak2 by AG490 significantly reverses stimulation of SAA3 mRNA by IL-6 without affecting basal SAA3 synthesis. Therefore, these data support Jak2 as a principal positive mediator of IL-6induced SAA3 gene expression. Stat- 1 and -3 , and SH2domain-containing tyrosine phosphatase (SHP) 2 bind to tyrosine-phosphorylated gp130 and stimulate downstream signaling proteins including p44/42 MAP kinase, p38 MAP kinase and PI 3-kinase (Heinrich et al. 1998). Since pharmacological inhibition of $\mathrm{p} 44 / 42$ MAP kinase and PI 3-kinase by PD98059 and LY294002, respectively, increases basal and IL-6-induced SAA3 synthesis, both signaling proteins might be negative mediators of SAA3 mRNA expression. In contrast, p38 MAP kinase is probably not involved in basal and IL-6-induced SAA3 synthesis.

Furthermore, TNF $\alpha$ is closely linked to obesityassociated insulin resistance and cardiovascular disease (Hotamisligil et al. 1993). Consistent with previous data (Lin et al. 2001) we find strong stimulation of SAA3 by $\mathrm{TNF} \alpha$ in the current study further supporting the notion that SAA3 might be an important mediator of cardiovascular disease and insulin resistance in states of increased TNF $\alpha$ levels such as obesity. In contrast, we do not find an effect of insulin, $\mathrm{GH}$ or the $\beta$-adrenergic agonist isoproterenol on SAA3 expression in 3T3-L1 adipocytes in vitro, pointing to the fact that this acute-phase reactant is not involved in insulin resistance and endothelial dysfunction induced by these hormones (Reaven et al. 1996, Gerich 1998, Frank 2001).

Taken together, we demonstrate for the first time that glucocorticoids and IL-6, beside TNF $\alpha$ and lipopolysaccharide, are potent stimulators of SAA3 expression in 3T3-L1 adipocytes in vitro. Furthermore, we present evidence that the positive effect of IL-6 is mediated via Jak2. These data indicate that stimulation of SAA3 expression in fat is a selectively regulated mechanism that might constitute an important element in the pathogenesis of insulin resistance, obesity and associated cardiovascular disease.

\section{Acknowledgements}

This work was supported by grants from the Deutsche Diabetes Gesellschaft (DDG) and the Buding Stiftung (to
M F). The authors declare that there is no conflict of interest that would prejudice the impartiality of this scientific work.

\section{References}

Andrews RC \& Walker BR 1999 Glucocorticoids and insulin resistance: old hormones, new targets. Clinical Science 96 513-523.

Fasshauer M \& Paschke R 2003 Regulation of adipocytokines and insulin resistance. Diabetologia 46 1594-1603.

Fasshauer M, Klein J, Neumann S, Eszlinger M \& Paschke R 2001 Isoproterenol inhibits resistin gene expression through a $\mathrm{G}(\mathrm{S})$-protein-coupled pathway in 3T3-L1 adipocytes. FEBS Letters $\mathbf{5 0 0} 60-63$.

Fasshauer M, Klein J, Neumann S, Eszlinger M \& Paschke R 2002 Hormonal regulation of adiponectin gene expression in 3T3-L1 adipocytes. Biochemical and Biophysical Research Communications 290 1084-1089.

Fasshauer M, Klein J, Lossner U \& Paschke R 2003a Interleukin (IL)-6 mRNA expression is stimulated by insulin, isoproterenol, tumour necrosis factor alpha, growth hormone, and IL-6 in 3T3-L1 adipocytes. Hormone and Metabolic Research 35 147-152.

Fasshauer M, Kralisch S, Klier M, Lossner U, Bluher M, Klein J \& Paschke R 2003b Adiponectin gene expression and secretion is inhibited by interleukin-6 in 3T3-L1 adipocytes. Biochemical and Biophysical Research Communications 301 1045-1050.

Fasshauer M, Kralisch S, Klier M, Lossner U, Bluher M, Klein J \& Paschke R 2004a Insulin resistance-inducing cytokines differentially regulate SOCS mRNA expression via growth factor- and Jak/Stat signaling pathways in 3T3-L1 adipocytes. Journal of Endocrinology 181 129-138.

Fasshauer M, Klein J, Kralisch S, Klier M, Lossner U, Bluher M \& Paschke R 2004b Growth hormone is a positive regulator of adiponectin receptor 2 in 3T3-L1 adipocytes. FEBS Letters $\mathbf{5 5 8}$ $27-32$.

Frank SJ 2001 Growth hormone signalling and its regulation: preventing too much of a good thing. Growth Hormone and IGF Research 11 201-212.

Gerich JE 1998 The genetic basis of type 2 diabetes mellitus: impaired insulin secretion versus impaired insulin sensitivity. Endocrine Reviews 19 491-503.

Heinrich PC, Behrmann I, Muller-Newen G, Schaper F \& Graeve L 1998 Interleukin-6-type cytokine signalling through the gp130/Jak/STAT pathway. Biochemical Journal 334 297-314.

Hotamisligil GS, Shargill NS \& Spiegelman BM 1993 Adipose expression of tumor necrosis factor-alpha: direct role in obesity-linked insulin resistance. Science 259 87-91.

Kubota N, Terauchi Y, Yamauchi T, Kubota T, Moroi M, Matsui J, Eto K, Yamashita T, Kamon J, Satoh H et al. 2002 Disruption of adiponectin causes insulin resistance and neointimal formation. Journal of Biological Chemistry 277 25863-25866.

Laborda J 1991 36B4 cDNA used as an estradiol-independent mRNA control is the cDNA for human acidic ribosomal phosphoprotein PO. Nucleic Acids Research 193998.

Lin Y, Rajala MW, Berger JP, Moller DE, Barzilai N \& Scherer PE 2001 Hyperglycemia-induced production of acute phase reactants in adipose tissue. Journal of Biological Chemistry 276 42077-42083.

Meek RL, Eriksen N \& Benditt EP 1992 Murine serum amyloid A3 is a high density apolipoprotein and is secreted by macrophages. PNAS 89 7949-7952.

Pickup JC \& Crook MA 1998 Is type II diabetes mellitus a disease of the innate immune system? Diabetologia 41 1241-1248.

Pickup JC, Mattock MB, Chusney GD \& Burt D 1997 NIDDM as a disease of the innate immune system: association of acute-phase reactants and interleukin-6 with metabolic syndrome X. Diabetologia 40 1286-1292. 
Pradhan AD, Manson JE, Rifai N, Buring JE \& Ridker PM 2001 C-reactive protein, interleukin 6 , and risk of developing type 2 diabetes mellitus. Journal of the American Medical Association 286 327-334.

Reaven GM, Lithell H \& Landsberg L 1996 Hypertension and associated metabolic abnormalities - the role of insulin resistance and the sympathoadrenal system. New England Journal of Medicine 334 374-381.

Ridker PM 1999 Inflammation, atherosclerosis, and cardiovascular risk: an epidemiologic view. Blood Coagulation and Fibrinolysis $\mathbf{1 0}$ Suppl S9-S12.

Stith RD \& Luo J 1994 Endocrine and carbohydrate responses to interleukin-6 in vivo. Circulation and Shock 44 210-215.

Tsigos C, Papanicolaou DA, Kyrou I, Defensor R, Mitsiadis CS \& Chrousos GP 1997 Dose-dependent effects of recombinant human interleukin-6 on glucose regulation. Journal of Clinical Endocrinology and Metabolism 82 4167-4170.
Weisberg SP, McCann D, Desai M, Rosenbaum M, Leibel RL \& Ferrante AWJ 2003 Obesity is associated with macrophage accumulation in adipose tissue. Journal of Clinical Investigation 112 1796-1808.

Wellen KE \& Hotamisligil GS 2003 Obesity-induced inflammatory changes in adipose tissue. Journal of Clinical Investigation $\mathbf{1 1 2}$ 1785-1788.

Xu H, Barnes GT, Yang Q, Tan G, Yang D, Chou CJ, Sole J, Nichols A, Ross JS, Tartaglia LA \& Chen H 2003 Chronic inflammation in fat plays a crucial role in the development of obesity-related insulin resistance. Journal of Clinical Investigation 112 1821-1830.

Received 12 February 2004

Accepted 7 September 2004

Made available online as an Accepted Preprint

16 September 2004 